\title{
A public-private partnership to transform online education through high levels of academic student support
}

\author{
Chris Walsh, Abhinav Mital ${ }^{a}$, Michael Ratcliff, Ana Yap, Zeina Jamaleddine \\ Victoria University, ${ }^{a}$ LINC Education, Singapore
}

\begin{abstract}
Online education often struggles to maintain a consistent, high quality academic experience. High attrition rates and low student satisfaction continue to challenge higher education providers. We present an innovative public-private partnership that delivers a resourcessufficient model of fully online postgraduate education with high levels of academic student support in an unbundled approach. The partnership overcomes the challenges that plague online education by leveraging learning analytics to provide highly responsive student support, 7 days a week and in the evenings. The success of this model is its ability to ameliorate problems inherent in online education. This includes the lack of ongoing staff training and support to successfully teach online, staff availability when students need support and insufficient staff-student ratios. As the sector moves towards a digitally integrated future, our model of online education illustrates how a public-private partnership can provide online learning that is effective as measured by high rates of student retention and transition, satisfaction, and academic success. We argue our resources-sufficient model provides a transformational roadmap for scaled online learning that creatively reimagines supported, personalised, engaged and student-centred digital learning as the sector moves towards a digitally integrated future.
\end{abstract}

\section{Implications for practice or policy}

- Public-private partnerships can represent a rebundling of the university that explicates how the university should work to provide responsive, supported, and high-quality online education.

- A resources-sufficient model of online education characterised by high levels of ongoing staff training, learning analytics to track student engagement, and optimum staff-student ratios, increases student retention and transition, satisfaction, and academic success.

- Student engagement systems that leverage learning analytics can work to increase students' academic success and decrease attrition rates.

Keywords: online education, student support, unbundling, public-private partnerships, learning analytics, student retention

\section{Introduction}

The idea of unbundling the university is not new (Craig, 2015; Komljenovic \& Robertson, 2016; Lewis \& Shore, 2019; Swinnerton et al., 2018, Tucker \& Neely, 2010). Australian examples are beginning to emerge from the formal discourse theorising successful educational partnerships (Gallager, 2014; Halloran \& Friday, 2018; Norton, 2013), but how they look in practice needs further exploration. Our collaboration, initiated under that warrant, presents an innovative and agile private-public partnership that delivers a model of fully online postgraduate education with high levels of responsive academic student support.

A number of universities across Australia are unbundling aspects of online course delivery to mitigate longstanding problems in the provision of online education including: high attrition rates (Greenland \& Moore, 2014; Haydarov et al., 2013; Moore, \& Greenland, 2017; Oregon et al., 2018; Patterson \& McFadden, 2009; Simpson, 2012; low completion and persistence rates ( $\mathrm{Li} \&$ Wong, 2019); and length of unit (Diaz \& Cartnal, 2006; Harwood et al., 2018; Jordan, 2015). This led to significant changes in the design and delivery of courses and individual units or subjects (Jaggars \& Xu, 2016; Pittenger \& Doering, 2010; Tait, 2018; Viberg \& Grönlund, 2018); student support (Simonson et al., 2019; Simpson, 2012 Tait, 2015); and student engagement and intervention strategies (Choi et al., 2018; Dixson, 2010; Revere \& Kovach, 2011; Sancho-Vinuesa et al., 2013). Even with these changes, numerous universities, due to traditional bureaucratic structures, remain resistant to change (Barcan, 2016) and continue to under resource online courses and risk not achieving quality online education at scale (Adair \& Diaz, 2014; Coalition of Academic Workforce, 2012; Thompson \& Kuhne, 2014). As a result, many universities struggle to successfully 
deliver online postgraduate education as measured by students' satisfaction, academic success, continuation, completion, and transition rates (i.e., from a Graduate Certificate into another postgraduate course).

Both within Australia and globally, public-private or third-party providers now assist universities to successfully deliver online postgraduate education and enrol students into online courses through a range of fee-for-service and revenue share agreements. As part of a comprehensive and innovative unbundled model, Victoria University (VU) Online works in successful partnerships with multiple third-party providers to leverage their expertise in enrolment services and marketing, aspects of online course management, and integrating academic support in its value chain. Even though online learning design and build services are often also available from third-party providers, VU Online Pty Ltd, a wholly owned university subsidiary that authors, builds, and delivers Victoria University's fully online courses, did not decouple learning design in a completely unbundled value chain where course build was fully outsourced. To do so would ignore the nexus of teaching and research that is central to high-quality and supported online teaching, as well as learning design and user experience, which is grounded in heutagogy or selfdetermined learning (Agonács \& Matos, 2019; Blaschke, 2012; Sivarajah et al., 2019).

VU Online's block model of postgraduate education is unique in the way it operationalises multiple layers of highly responsive academic and non-academic student support, experiential learning design, bespoke facilitator training, and learning analytics to increase student engagement through personalised interventions. The public-private partnership we present here simultaneously represents a rebundling of the university that explicates how the university could work and how it might operate when it comes to responsive, supported, and high-quality online educational provision (Lewis \& Shore, 2019; Philips, 2017). VU Online's block model of postgraduate online education, explored below, represents an imagined reinvention and simultaneous critique of the sector that permits VU Online to not only generate revenue for the university, but also add value and assist the university in achieving its vision and mission.

In what follows, we first describe our work to unbundle the university through creating a university owned private company and involving third-party stakeholders to take up the challenge of successfully launching online courses in a highly contested market. We also describe VU Online's postgraduate block model and its underlying principles that demand high levels of student support to achieve personalised, active, and student-centred digital learning. We then articulate how our third-party partnership provides high levels of academic student support through ongoing training and professional development. We also provide an overview of how the partnership leverages real-time data analytics to support students' online study in a cost-effective way to assure student engagement. In conclusion, we outline the impact of working in partnership and describe how it affects university policy and provides a roadmap for scaled online learning characterised by engaged learning and high levels of responsive student support.

\section{Unbundling the university}

There were a number of drivers that lead to formation of VU Online Pty Ltd, the most critical being Victoria University's limited online course offerings in the Australian market. Victoria University's first fully online course was launched by VU Online in September 2018. As a relative latecomer to the provision of online education in Australia, VU Online was uniquely well positioned to learn as much as possible from its predecessors and design an innovative model of online education specifically designed to achieve Victoria University's mission of providing career-based education, in block mode, to students from the west of Melbourne and beyond. This opportunity created a strategic imperative to enter an increasingly critical segment of the education sector and broaden Victoria University's enrolment base. This imperative was driven by challenging conditions due to changes in funding arrangements and the capping of Commonwealth supported places (Norton \& Cherastidtham, 2018) when Victoria University's on-campus enrolments were historically low. Given the external environment in 2018, Victoria University needed to increase and broaden its revenue streams as it pursued a transformative agenda. Specifically, it launched VU Online and the introduction of the First Year Model in 2018, also known as the block model, a Swedish teaching model where students focus on one unit for 4 intensive weeks, before moving onto the next unit in 8 consecutive study periods.

Over the first 9 months of 2018, VU Online began operationalising the business and successfully launched an online MBA in September to target the largest segment of the online market, mature-age students (aged 
25 to 40) seeking qualifications for employment advancement purposes. Commissioned research indicated this segment has a natural home within Victoria University's existing brand profile and was growing at solid rates. To appeal to this market, VU Online formulated a customer value proposition that includes career-relevance, accelerated delivery, and high-levels of student support. Then, VU Online designed a bespoke postgraduate block model of education (https://vimeo.com/344202025) to realise its customer value proposition based on the following principles:

- Accelerated with 6 blocks per year in 8-week study periods (SP) with a 1-week break between blocks and over Easter, and a 4-week break in December/January.

- Consistent unit design and delivery where students know what to expect in terms of assessment due dates, online classes, and required time allocation for study.

- Experiential learning in which students learn through scenarios, case studies, assessments, and unit content that is relevant to their working lives.

- Industry-based self-determined assessments that focus on students acquiring industry and enterprise skills through research, enquiry and practice.

- Small online facilitator-supported classes with a maximum 25:1 student to online facilitator ratio.

- Proactive and prompt one-to-one student support - provided both asynchronously and synchronously, 7 days a week and in the evening.

Responding to internal market-research on pain points for online students, VU Online identified the layers of student support needed to successfully deliver its postgraduate block model. Then it actively sought out a third-party stakeholder to address insufficient staff-student ratios and to provide highly trained staff to successfully support students' online learning when they need that support most, primarily in the evenings and on the weekends.

\section{A public-private partnership to provide high levels of academic student support}

VU Online entered into a third-party partnership with LINC Education after witnessing the organisation's highly successful training program for online facilitators. Because online students typically do not have access to the same levels of academic support found in on-campus courses, LINC Education's solution, with visual dashboards that graphically display relevant student data (Pardo, 2014; Verbert et al., 2013), transforms the inadequacy of text based, public, and semi-synchronous channels of communication traditionally adopted in online education. Rather, it creates affordances for action, specifically ongoing engagement between facilitators and students (Beer et al., 2014).

VU Online's postgraduate block model, delivered in partnership with LINC Education, demonstrates a resources sufficient model, not often found in higher education, that provides a more personalised datadriven approach to students' academic support. Delivering VU Online's model addresses the key barriers to success and satisfaction for online students by integrating four layers of academic and non-academic support (https://vimeo.com/364187895). The first layer is an online unit facilitator, supplied by LINC Education, who provides 1:1 academic support via phone, email or SMS 7 days a week. Facilitators have an excellent track record of providing same-day responses to all student enquiries. The second layer of support comes from an online unit coordinator, a VU Online academic who delivers live weekly online office hours and fortnightly teaching seminars. A Student Success Advisor is the third layer of support, and on-hand Monday to Friday via phone and email, to help students with any non-academic queries. The final layer is a network of personalised IT, library, language, literacy, and numeracy support, as well as counselling services.

While VU Online's model is similar to other online program providers, it is the role of the online facilitator, provided by LINC Education, which is remarkably different in the case of VU Online. The online facilitator's primary objective is to proactively engage students in their learning activities. While facilitators still contribute to forums to moderate peer-supported learning activities, they primarily use mobile phone calls, texts, and emails to drive one-to-one discussions with students on specific issues they want to discuss related to unit content and assessments. During each unit's orientation week, VU Online facilitators email and send a text message to students' mobile phones introducing themselves and inviting students to get in touch with them via whichever medium and at whichever time is most suitable. Students then have the 
online facilitators' mobile phone number readably available, providing them with immediate and ongoing access to student support 7 days a week, and in the evenings.

\section{Ongoing online facilitator training}

In order to deliver the level of academic student support described-consistently_across all units, the online facilitators undergo approximately 40 hours of training covering all aspects of academic support they are expected to provide, as well as how to use LINC Education's student engagement system, LINCtrac, to contact, support, and track all facilitator-student interactions. All online facilitators undergo this 3-part mandatory training and coaching program. An online facilitator is appointed to a unit only after successful completion of their training. The first part of the training consists of online self-learning modules and assessments in conjunction with live interactions. This training covers foundational aspects of supporting online students (Figure 1). Process training culminates in a simulation activity that recreates an online classroom and tests the participants on their ability to handle different situations.

\section{LINC Process Training}

\begin{tabular}{|c|c|}
\hline Training Module & Agenda \\
\hline A. Fundamentals of online student support & $\begin{array}{l}\text { - Roles, expectations and responsibilities of online teaching team members } \\
\text { - } \quad \text { Student expectations in an online class } \\
\text { - Student success and early attrition indicators } \\
\text { - Student types and strategies for online support } \\
\text { - Things to avoid when teaching online }\end{array}$ \\
\hline B. Upholding academic integrity & $\begin{array}{l}\text { - Overview of academic integrity and misconduct } \\
\text { - Rules of maintaining academic integrity in student support } \\
\text { - Scenario exercises on academic integrity }\end{array}$ \\
\hline C. Best practices in online facilitation & $\begin{array}{l}\text { Role of the VU Online Facilitator } \\
\text { Activities of the VU Online Facilitator (introductory conversations, discussion } \\
\text { forum and learning activity management, proactive student check-ins, } \\
\text { resolving academic queries, grading and feedback) } \\
\text { Guidelines for each activity } \\
\text { Practice exercises for each activity } \\
\text { Coordinating with VU teams }\end{array}$ \\
\hline D. Time management & $\begin{array}{l}\text { - Understanding student learning behaviour } \\
\text { - Setting the student expectations for academic support } \\
\text { - Time allocation by activity and best practices for managing time }\end{array}$ \\
\hline E. Managing technology & $\begin{array}{l}\text { - Technology for student support (VU Collaborate, LINCtrac) } \\
\text { - Understanding functionality of each tool } \\
\text { Hands-on practice on LINCtrac }\end{array}$ \\
\hline
\end{tabular}

Figure 1. LINC Education's training modules and indicative content covered

The second part of LINC Education's training requires all facilitators to complete a suite of required Victoria University e-learning modules to prepare them to work within, and comply with Victoria University's policies, procedures and values. Part three of the online facilitators' training is ongoing coaching, where they receive a 30-minute customised coaching session with an experienced LINC mentor to continuously improve their student support expertise in fortnightly intervals. The mentor discusses the facilitator's performance in the past week in relation to metrics collected by LINCtrac, including student engagement, responsiveness, feedback, and compliance with university policies, procedures, and requirements. The ongoing coaching is a two-way process that allows for timely identification of issues faced by facilitators and provision of interventions required to maintain the highest quality and level of student support.

\section{Leveraging real-time data and learning analytics to support students' online study}

LINC Education's proprietary student engagement system, LINCtrac, uses learning analytics to personalise student support and generate deep student-driven insights. Very few educational organisations are using student engagement systems that work to increase students' academic success (Campbell et al., 2007; Gašević et al., 2015) and decrease attrition (Aguiar et al., 2014). LINCtrac's intervention-based learning 
analytics assists VU Online in improving student success by providing responsive and targeted student support via a technology solution that presents student data in a way that it can inform or trigger action (Clow, 2012). LINCtrac leverages the capabilities of Victoria University's LMS' (Brightspace) engagement dashboard to provide more comprehensive analytics that allow VU Online to increase student engagement and success within its postgraduate block model. LINCtrac operates in a way similar to the Moodle Engagement Analytics Plugin+ (MEAP+) described by Liu et al. (2017), as it creates solutions to student disengagement. However, LINCtrac is different because it takes into consideration a more holistic complexity of learner activity that is generated through tracked 1:1 phone calls, texts, and emails between the student and online facilitator, as well as the facilitators' interpretation and analysis of students' progress based on those interactions.

Data-driven personalisation of student support is a relatively new field that is largely absent from the learning analytics landscape (Liu et al., 2017; Liu et al., 2019; Tait, 2018). LINCtrac provides the necessary heuristics to detect students' disengagement in their online units and increases VU Online's predicative capabilities to action an intervention to engage students or provide them with targeted support. LINCtrac embeds multiple communication channels such as email, text, phone, and chat to communicate with students, all tracked and can be analysed within the software. All student to facilitator and facilitator to student communication, be it voice or text, is also recorded. Online facilitators take notes regarding each student interaction and these are also recorded in the system. LINCtrac's data analytics, process automation, and natural language processing (NLP) capabilities are then used to generate proactive and responsive engagement activities for the online facilitators. LINCtrac does this by suggesting a studentwise engagement plan for the online facilitator to follow, based on the interaction history and observations of the facilitator. LINCtrac ensures that online facilitators follow a high engagement process where the same level of personalisation and consistency is provided to all students.

In order to recommend a personalised engagement plan for each student, the platform utilises a set of variables which are generated from both the LMS or from the online facilitator's 1:1 interactions with the student. Table 1 outlines selected key source variables.

Table 1

Variables used by LINCtrac to nudge personalised student engagement

Variables generated from LMS Variables generated through 1-1 engagements

Last LMS login Date of last 1:1 interaction

Assignment due date $\quad$ Mode of last 1:1 interaction

Assignment submission status Facilitator's evaluation of student's progress

Number of units completed

The relationship between these variables and the probability of the student progressing from one milestone to the next is calculated periodically over the 6 weeks of teaching in each unit. This enables understanding of when the online facilitator should proactively intervene with students to maximise the effectiveness of their individualised support plans. For example, in each VU Online unit, the first assessment of the unit is due at the end of 2 weeks from the start of orientation week (i.e., in Week 1). The census date for the unit is on the Friday of the third week from orientation. An analysis of data from 1367 student enrolments from study period 5 in September 2018 to study period 2 in March 2020, illustrates LINC Education is able to determine the following trends:

1. The probability of a new student not completing the unit is more than $80 \%$ if the student does not engage with their online facilitator within the first two weeks of the study period;

2. Any new student who has at least one phone conversation with the online facilitator, has a $88-90 \%$ probability of submitting the first assessment and remaining enrolled past census; and

3. Based on the one-to-one conversations, online facilitators using LINCtrac can identify the percentage of new students at high risk of not submitting the first assessment. (In this case, online facilitators take steps to proactively engage or re-engage these students. Data indicates that nearly 
half of these students who are engaged or re-engaged end up successfully progressing, reducing the overall attrition rates of new students by approximately $5 \%$ ).

The timing of each of these interactions is critical to determine which students are falling behind on their assessment milestones and are at risk. This is illustrated in Figure 2, which demonstrates that the probability of non-submission of assessment 2 increases when a student does not engage with the LMS or facilitators during certain windows ahead of the assessment due date.

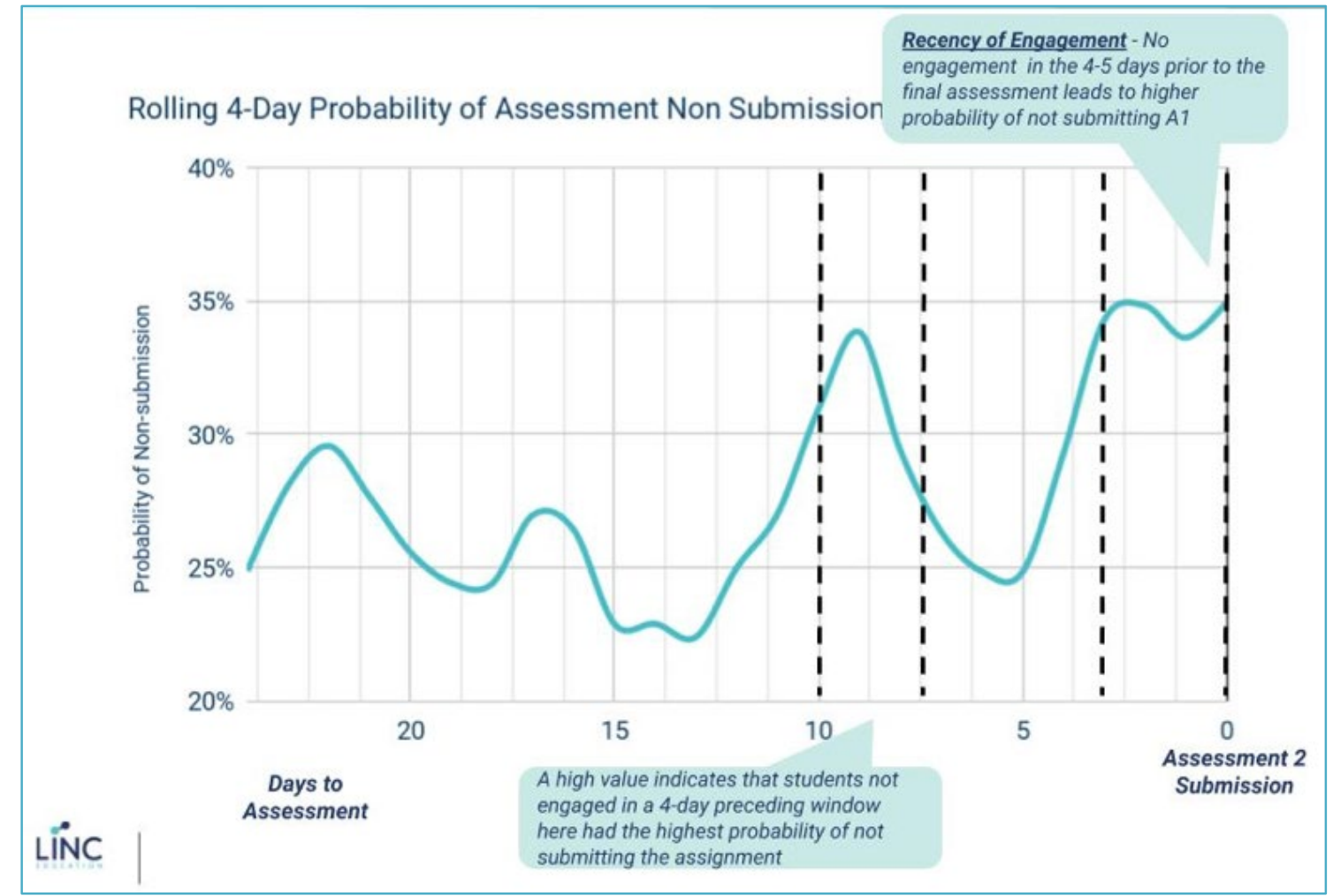

Figure 2. Probability of student non-submission of assessment

When this happens, LINCtrac's Activity Centre then alerts the online facilitator that an intervention is needed (Figure 3). Once the facilitator communicates with the student, they can judge their academic progress and provide necessary personalised support. LINCtrac replicates this behaviour across the entire student cohort in the unit, and uses the data streams to calculate the risk associated with each student. It then categorises students in groups and actively prompts the facilitator to engage with the students who are at risk. This allows the online facilitator to prioritise their own work flow and proactively contact students who are at greater risk of discontinuing or falling behind. 


\begin{tabular}{|c|c|c|c|c|c|c|}
\hline L $\mathbb{I N D}_{\mathrm{W}}^{\infty} \mathrm{N} C$ & \multicolumn{4}{|c|}{$\begin{array}{l}\text { LINC Demo - LINC Demo Training Unit } \\
\text { LINC Test University • Mon, } 29 \text { Jul - Thu, } 22 \text { Aug }\end{array}$} & $\begin{array}{l}\text { Your Time (SGT) } \\
\mathbf{0 7 . 4 6} \mathrm{pm} \\
\text { Thu, } 26 \mathrm{Sep}\end{array}$ & $\begin{array}{l}\text { University Time (ACST) } \\
09.16 \text { pm } \\
\text { Thu, } 26 \text { Sep }\end{array}$ \\
\hline $\begin{array}{l}\text { Welcome, } \\
\text { Tester }\end{array}$ & \multicolumn{4}{|c|}{ Student Activities for Today } & \multirow[t]{7}{*}{ No new messages } & \\
\hline $\begin{array}{l}\text { Home } \\
\text { Classroom }\end{array}$ & 田 & $\begin{array}{l}\text { Parth: Introduction \& Onboarding OVERDUE } \\
\text { An SMS was sent to Parth PND }\end{array}$ & Call student & $\begin{array}{l}\text { Was due by } \\
10.00 \text { pm } \\
\text { Mon, } 19 \text { Aug }\end{array}$ & & \\
\hline $\begin{array}{l}\text { Appointments } \\
\text { Other Inbox }\end{array}$ & '(C)' & $\begin{array}{l}\text { Anoop: Proactive Email Check-in: } 3: 22 \ldots \\
\text { All reminders removed for this activity }\end{array}$ & $\begin{array}{l}\text { Select follow-up } \\
\text { action }\end{array}$ & $\begin{array}{l}\text { Was due by } \\
07.09 \mathrm{pm} \\
\text { Fri, } 13 \text { Sep }\end{array}$ & & \\
\hline $\begin{array}{l}\text { KPIs } \\
\text { Unit Info }\end{array}$ & $\stackrel{\uparrow}{\natural}$ & $\begin{array}{l}\text { Amit: Proactive Check-in OVERDUE } \\
\text { Activity was marked as completed and a note was added }\end{array}$ & Review status & $\begin{array}{l}\text { Was due by } \\
06.41 \mathrm{pm} \\
\text { Tue, } 17 \text { Sep }\end{array}$ & & \\
\hline \multirow[t]{3}{*}{ Help } & '()' & $\begin{array}{l}\text { Adhnan: Introduction \& Onboarding OVERDUE } \\
\text { All reminders removed for this activity }\end{array}$ & $\begin{array}{l}\text { Select follow-up } \\
\text { action }\end{array}$ & $\begin{array}{l}\text { Was due by } \\
\text { 11.58am } \\
\text { Thu, } 19 \text { Sep }\end{array}$ & & \\
\hline & 0 & $\begin{array}{l}\text { Pranav: Proactive Check-in OVERDUE } \\
\text { Email sent, } 2 \text { emails in conversation }\end{array}$ & Call student & $\begin{array}{l}\text { Was due at } \\
\text { O6.35pm } \\
\text { Sat, 21 Sep }\end{array}$ & & \\
\hline & 6 & $\begin{array}{l}\text { Abhinav: Proactive Check-in OVERDUE } \\
\text { Note added for an unsuccessful call | Duration 00:00secs }\end{array}$ & $\begin{array}{l}\text { Select follow-up } \\
\text { action }\end{array}$ & $\begin{array}{l}\text { Was due by } \\
10.50 \mathrm{am} \\
\text { Wed, } 25 \text { Sep }\end{array}$ & & \\
\hline
\end{tabular}

Figure 3. LINCtrac's Activity Centre nudging facilitators to engage with individual students

For returning students in the next unit, a different set of probabilities apply. These probabilities then change as the cohort progresses from the first assessment to the next. The platform analyses all of this information in real-time to produce workflow directives for the online facilitators, and thus makes it very easy for them to responsively and actively engage students. LINCtrac ensures a consistent learning analytics approach to student engagement is applied across units and facilitators, thereby achieving equitable and quality student support and engagement at scale. LINCtrac platform's data insights allow VU Online and LINC Education to co-monitor the efforts and outputs of all of the online facilitators in real-time. It captures both unit level engagement and individual student and facilitator engagement. LINCtrac relays qualitative information and feedback generated by the online facilitators from their conversation with the students back to the unit leadership and program management teams in real-time (Figure 4). This includes quantitative analysis of student issues, topics of discussion as well as the online facilitator's ongoing assessment of a student's progress. Working in partnership with LINC Education, VU Online no longer needs to wait until the end of the study period to receive students' feedback. Instead, it can identify and resolve issues around student support and teaching and learning as they arise and take proactive, as well as corrective action immediately in real-time.

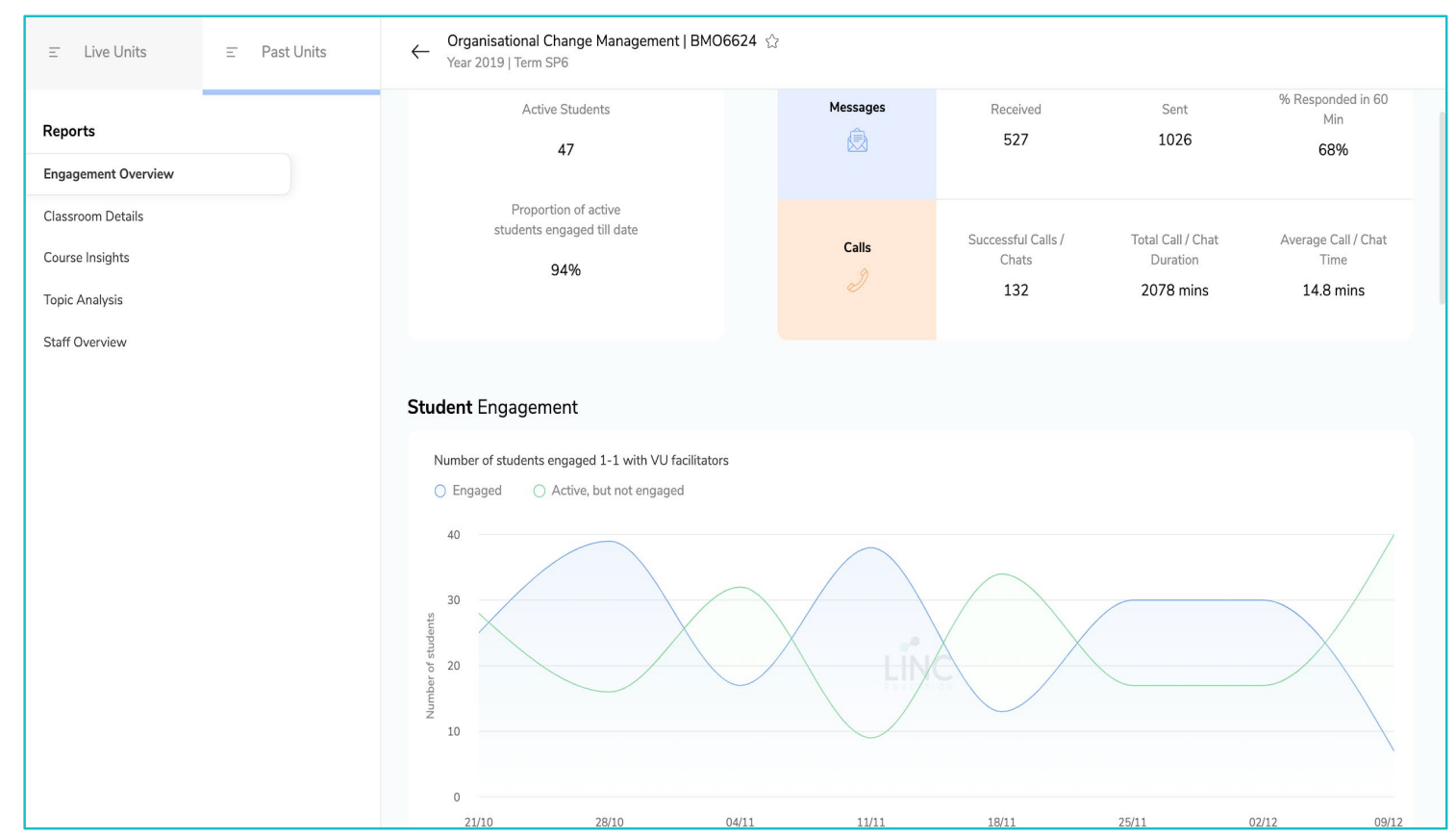

Figure 4. LINCtrac's Insight Portal available to VU Online for live monitoring of student engagement and course insights 


\section{The successful impact of the unbundled approach to online education}

VU Online's new online learning model delivered in postgraduate block mode, strengthened by the partnership with LINC Education, has been successful in achieving its targets and business outcomes and is a viable proof of concept. To date, in just 21 months since launch, VU Online has:

- launched five $100 \%$ online postgraduate courses in a university that previously had none, generating millions of dollars in revenue;

- $\quad$ enrolled 322 continuing students, successfully winning market share in a saturated market;

- continuously delivered on its customer value proposition to provide high levels of academic support to students;

- achieved online postgraduate enrolments in Business Administration that far outnumber oncampus enrolments: 301 (VU Online) compared to 38 2018-YTD (on campus);

- limited rates of student attrition to $21 \%$ compared to $27 \%$ in other online postgraduate courses in Australia (Department of Education and Training, 2019);

- $\quad$ achieved high rates of student satisfaction as measured by the Student Evaluation of Unit (SEU) and LINC Education's Midterm Survey;

- $\quad$ achieved high rates of unit continuation (87\%), completion (90\%), and progression (67\%) (Table 2);

- $\quad$ achieved high rates (74\%) of transition from one course to the next (from the Graduate Certificate in Business Administration to the MBA) within 1 year of graduating;

- engaged in robust research, with ethics approval, to understand students' beliefs about the academic support they have received; and

- commenced preparation for three additional postgraduate courses in finance and public health for launch in July 2020 and January 2021 respectively.

Table 2

VU Online's rates of students' continuation and completion

\begin{tabular}{lrrr}
\hline Period summary statistics (SP2 2018 to SP3 2020) & Total & New & Returning \\
\hline Commencing students & 1367 & 407 & 960 \\
Enrolment at census & 1188 & 322 & 866 \\
Commencement to census continuation rate & $87 \%$ & $79 \%$ & $90 \%$ \\
Student completions (up until SP2, 2020) & 895 & 245 & 650 \\
Unit completion rate (up until SP2, 2020) & $90 \%$ & $86 \%$ & $91 \%$ \\
Study Period 1 to Study Period 2 progression rate & $76 \%$ & & \\
\hline
\end{tabular}

The partnership generates real-time quality metrics on levels of student engagement, responsiveness, and process compliance. The partnership highlights exceptions where the performance levels on major metrics fall below threshold values. Mentoring and coaching processes are in place to ensure all needed interventions are implemented as quickly as possible to increase online teacher performance above threshold levels. To get an understanding of both the kind, and amount, of support provided to students, Figure 5 reports the total number of phone conversations, total conversation time, average time per conversation, and average time per student across the 16 units delivered from the launch of the MBA in September 2018 to April 2020. The metrics also report the total student discussion board posts responded to and total emails/SMS exchanged and the response time to students' messages, usually emails (e.g., within 12 hours, 60 minutes post $5 \mathrm{pm}$, and 60 minutes before $5 \mathrm{pm}$ ). The metrics demonstrate the success of VU Online's student support since launch in the 16 postgraduate business administration units with 1022 students using the one-to-one support. 


\section{Student Engagement}

\section{Facilitators engaged with students over $~ 1090$ hours of 1-1 conversations and $\sim 54650$ email / SMS exchanges}

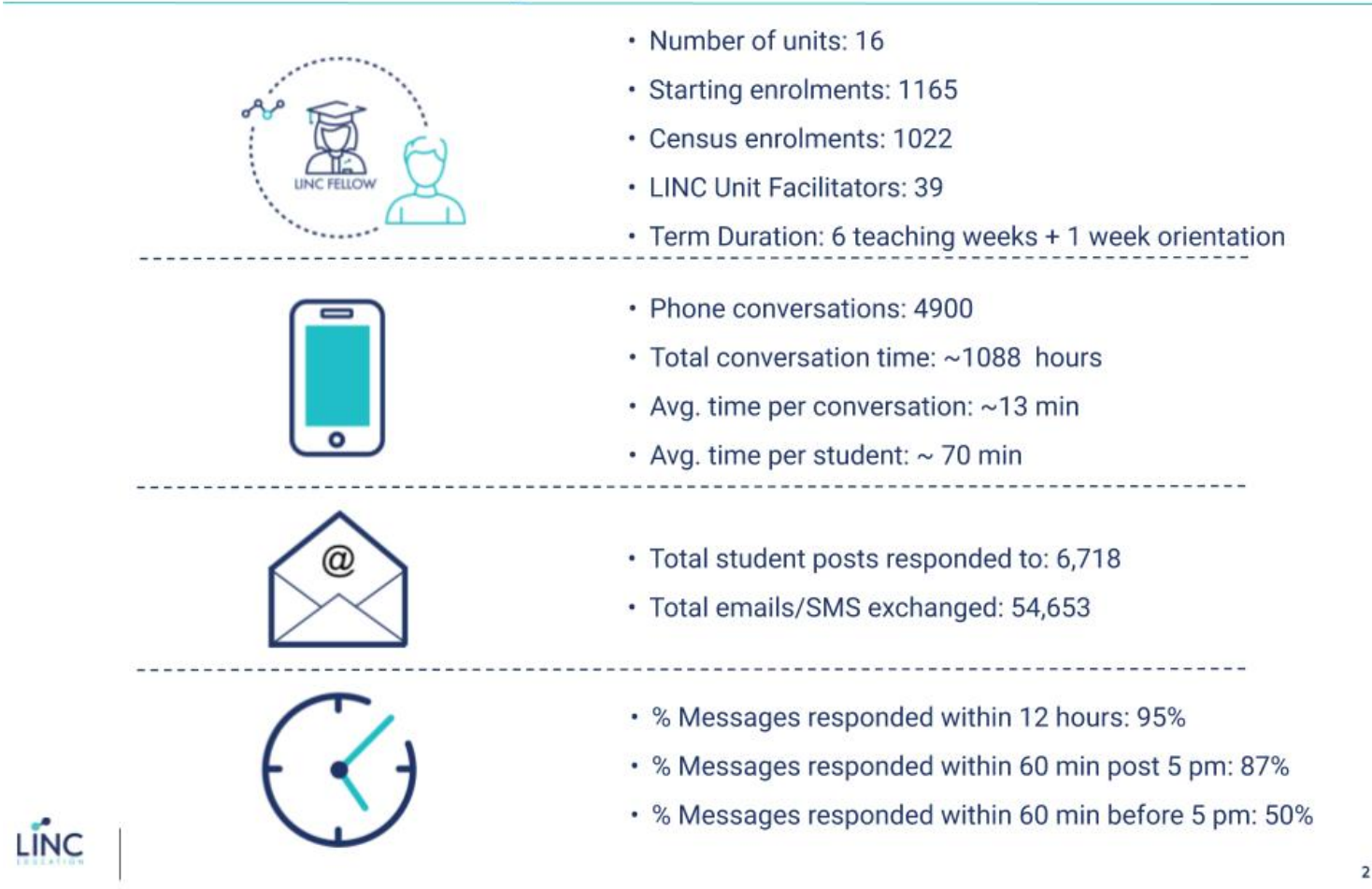

Figure 5. Student engagement metrics in VU Online's postgraduate block model

\section{Student satisfaction}

VU Online collects feedback from students primarily through two channels, VU's official Student Evaluation of Unit (SEU) and an anonymous mid-unit survey administered through LINC Education, and sent to students' mobile phones. For the 16 postgraduate business units delivered from September 2018 to May 2020 the SEU feedback has been above the university average, whereas typically online programs tend to have lower satisfaction than on-campus programs. The SEU survey consists of six Likert scaled questions and two open questions (Figure 6).

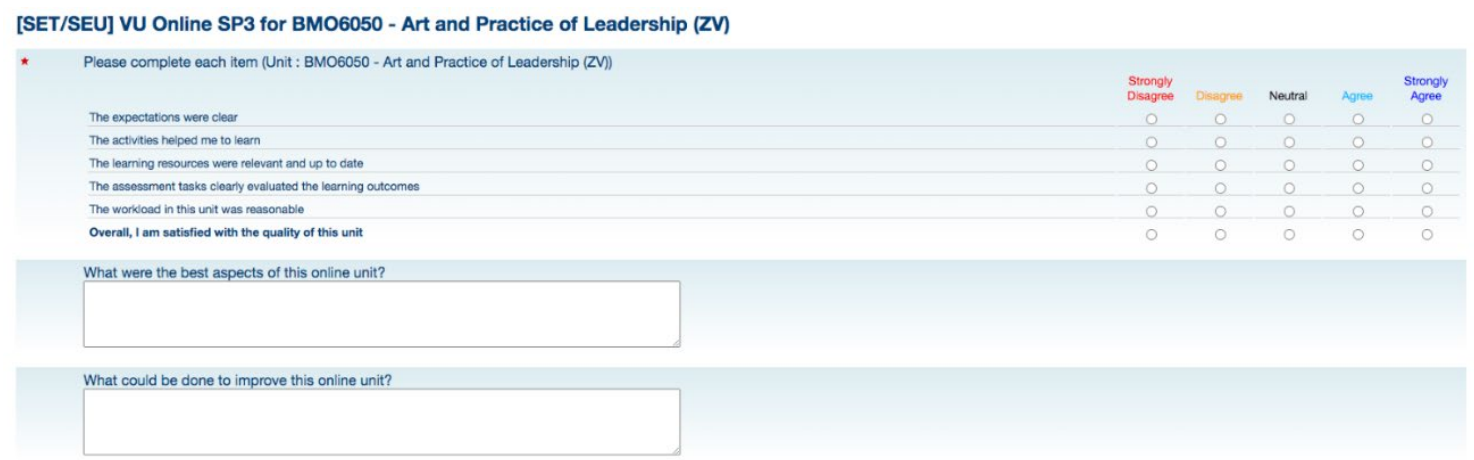

Figure 6. VU Online Student Evaluation of Unit survey

The SEU measures responses to the six questions both on a 5-point Likert scale. For the Business units delivered from September 2018 to May 2020, the mean responses were 4.2, 4.1, 4.2, 4.1, 3.9, and 4.0 for each question respectively, where $90 \%$ of students agree that the expectations were clear and $84 \%$ of students were satisfied with the quality of the unit. The qualitative data, by and large, illustrates students reporting very positively on the units as well as teaching and support provided by both the unit coordinators and unit facilitators (Table 3). A careful analysis of the overall score for each SEU question highlights that 
all units had positive student comments, specifically in relation to the support including in units where the score for a question was reported under 4. This demonstrates the high levels of student satisfaction and continuous improvement across VU Online units where 12 out of 16 new online unit iterations that ran across the span of 19 months scored above a mean of 4.0 .

Table 3

Students' responses to "What were the best aspects of this unit?"

Survey comment

"The support from the facilitator ..."

"The online facilitators support, teaching, online seminars and office hours"

"The assistance of the facilitators was awesome, gave me the time required to help me process and understand concepts of this unit"

"I loved the prompt feedback from my online facilitator and the encouragements from the lecturer. They guided me and ensured that I did not go off track in my assignments and always pointing me in the right direction on what I should focus on!"

"Exceptionally helpful and passionate facilitators"

"The unit facilitators were available $24 / 7$ to assist with any enquiries. All the teaching staff were extremely knowledgeable and approachable."

"Excellent facilitator and super unit coordinator ..."

"The availability and time given from my Facilitator has been good! Always supportive and insightful with all the work required."

Over the same period the midterm survey (administered in week 3 of 6) indicates VU Online's student support is highly responsive, available, friendly, and useful (Figure 7). Qualitative feedback from these surveys also included very positive comments on the support from the unit facilitators (Table 4). Data from 475 student surveys was collected where students rated the support on a 5-point Likert scale (5 being highest).

Student Satisfaction

Mid Term Survey: Satisfaction with facilitators was $\sim 4.6$ on 5 across the

three key parameters

Mid-Term Student Survey ( $N=679,68 \%$ of census students)
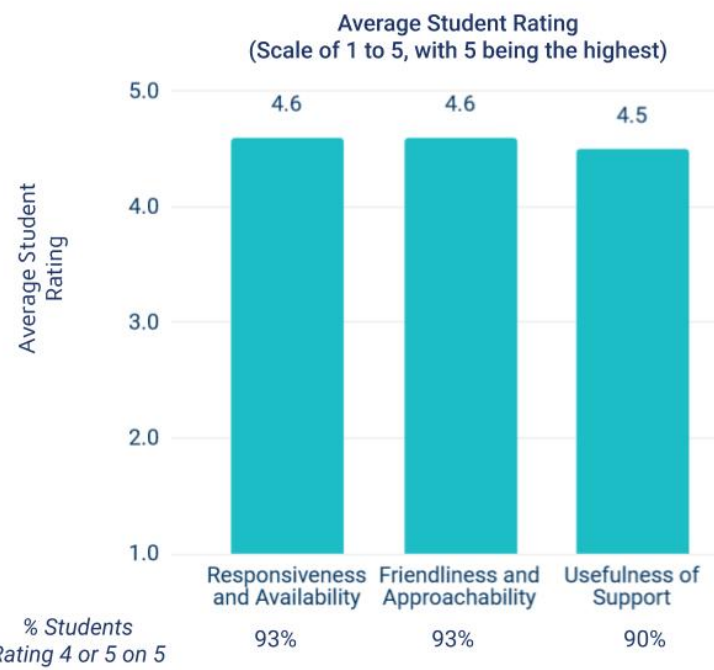

Figure 7. Results from LINC Education's midterm survey 
Table 4

Samples of students' qualitative comments on the mid-term surveys (2018-2020) in postgraduate business units

Survey comment

"[Facilitator name] has been exceptional in his support to me. Always available to discuss business topics and the course."

"He is really nice and always there to help. I was really overwhelmed by online study for the first time and I was about to drop the course, but. He supported me to the degree that not only I build up the confidence to my assessment, but also I achieved a distinction."

"Couldn't do it without her."

"My facilitator has been instrumental in helping me navigate the unit and answering any questions or queries I may have."

"[Facilitator name] is magnificent...she has been a shining light."

"Genuinely appreciate and rely on [facilitator name] support. She is absolutely across the subject and provides quick and relevant support and feedback."

"[Facilitator name] has been friendly and professional throughout. She is very mindful of my own busy schedule and is willing to discuss topics at any hours. She is a credit to her position."

"[Facilitator name] is an awesome facilitator. She helps by guiding and explaining topics for me."

\section{Academic success}

VU Online students have also experienced high levels of academic success in the online postgraduate block model, complementing the undergraduate block model that also launched in 2018 where undergraduate students also experienced high levels of academic success (Rosanes, 2020). Similar to the on-campus block model, the online postgraduate block model's academic support, where students receive prompt and targeted support, has seen remarkable results in terms of students' academic success. Since its launch in study period 5 of 2018 until study period 2 2020, to date, $90 \%$ out of a total of 834 unit attempts were passes with $8 \%$ achieving Pass grades, 22\% achieving Credit grades, 37\% achieving Distinction grades and $23 \%$ achieving High Distinction grades (Figure 8.). There is also an upward trend in the data with pass rates for 2020 , to date, at currently $92 \%$ compared with $90 \%$ in 2019 and $86 \%$ in 2018 . This demonstrates the success of VU Online's resources-sufficient model's and student support in achieving positive student outcomes in terms of academic success. 


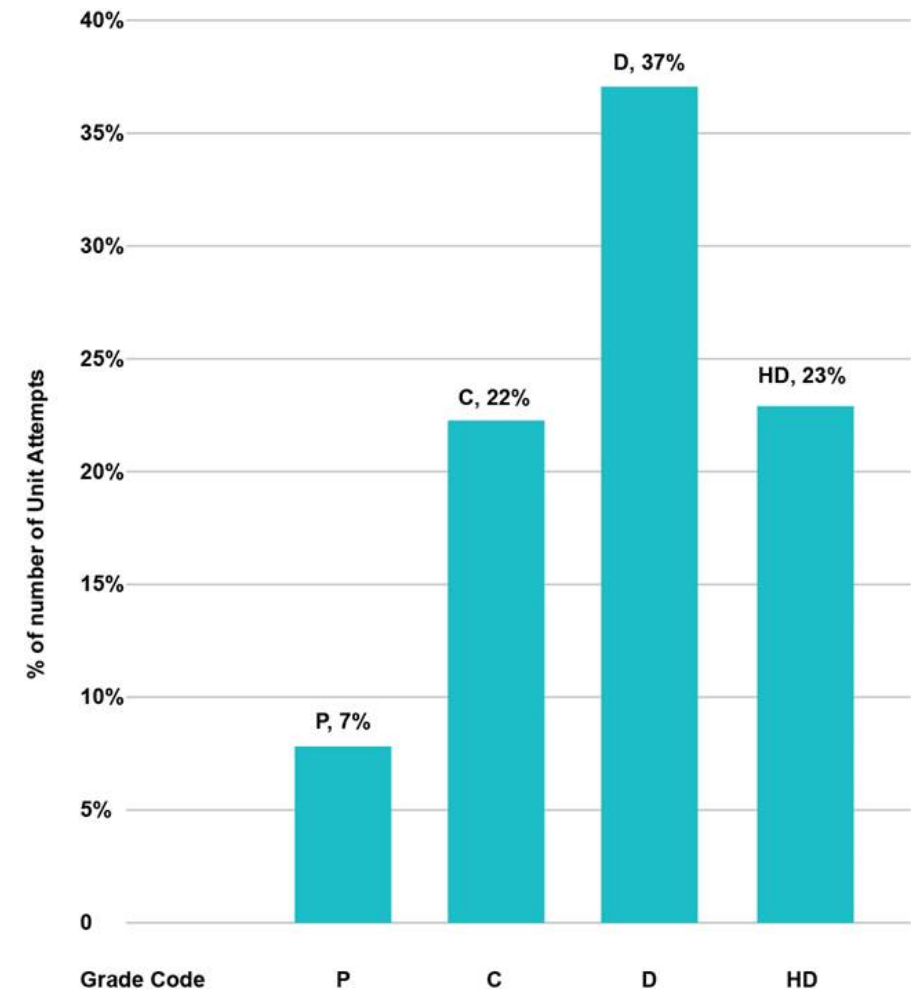

Figure 8. VU Online's Grade Distribution Study Period 5 of 2018 until Study Period 22020

\section{Implications for educational technology policy and practice}

Attrition rates in higher education have long been the Achilles' heel of fully online delivery (Greenland \& Moore, 2014; Haydarov et al, 2013; Moore \& Greenland, 2017; Stone, 2019). VU Online's postgraduate block model, delivered in a third-party partnership with LINC Education, is an approach that has been costeffective and successful at reducing attrition rates, increasing continuation and completion rates, and improving students' academic success. The partnership also successfully demonstrates how well-trained online facilitators, who receive ongoing professional development, can impact positively on students' academic success. The partnership's focus on the use of data and learning analytics, that moves beyond those available in the university's LMS, to improve students' learning experience by alerting the online facilitator that an intervention is needed can be replicated at scale to improve online education in higher education and beyond. But this has significant implications for educational policy at university level, that cannot be underestimated.

Regardless of the third-party relationship, critically, it is always the registered provider who is accountable for the quality of education and services delivered by a third-party partner on its behalf. More importantly it is up to the provider, in this case VU Online, to ensure compliance with the Higher Education Standards Framework (Threshold Standards) 2015 in Australia. VU Online and Victoria University take this responsibility seriously and rigorously monitor and quality assure our third-party partnership with LINC Education and other stakeholders, to systematically and regularly confirm we meet and continue to meet the Higher Education Standards (HES) Framework.

To ameliorate any risks to quality, Victoria University, similar to other Australian universities, has put a number of key policies and procedures in place that VU Online explicitly adheres to. This includes a Third Party Arrangements Policy, Third Party Arrangements Procedure, Review of Third Party Arrangements Procedure, Third Party Online Partnership Procedure, Third Party Licensing and Auspicing Procedure, and Third Party Arrangements Procedure (VET). These policies and procedures are wide ranging and set out the broad principles that underpin the delivery of Victoria University courses in partnership with our thirdparty providers. Important in any third-party partnership is communicating these policies and procedures with the third-party stakeholder so they fully understand VU Online's role in ensuring it, and its third-party partner, deliver any given course consistent with all of the requirements of the HES Framework. VU 
Online's relationship with LINC Education is excellent, because they have fully engaged with the HES Framework and all relevant TEQSA standards. Furthermore, LINC Education understands the inherent risks to quality that can arise when working in partnership and that any failures on the part of the provider are unacceptable to TEQSA.

A key concern for any Australian university or university entity entering into a third-party partnership is to assess that organisation's understanding of the HES Framework as well as the authority's approach to quality assurance and regulation. VU Online has encountered third-party providers who offer a range of services to assist universities to successfully deliver online postgraduate education, but struggle to understand the HES Framework and TEQSA's approach to regulation. Because the higher education provider must engage in robust and ongoing internal monitoring of the quality of their higher education activities, assisting third-party providers to understand both the intent of the standards, and risk to quality, is paramount. VU Online has designed what we call a TEQSA Third-Party Matrix that references TEQSA's Guidance Note: Third Party Arrangements and all of Victoria University's third-party policies and procedures. The matrix outlines topics for agreement with third-parties, the registered provider's responsibilities, the third-party's responsibilities, location of these responsibilities in relevant legal agreements, and support documentation (e.g., policies, procedures, guidance notes, standards, etc.). We found co-authoring the matrix an extremely useful activity to acknowledge and understand possible vulnerabilities and the risks that can arise in any third-party partnership. The matrix itself provides a useful framework for being anticipatory to avoid risks in the first place by ensuring expectations and critical responsibilities are clear and reasonable, and all quality controls and monitoring processes are in place to ensure a positive student experience that is compliant with TEQSA.

\section{Conclusion}

As the sector moves towards a digitally integrated future, the design of VU Online's postgraduate block model illustrates how in an unbundled model of online education, delivered in a public-private partnership can provide previously unimaginable student support 7 days a week and evenings. The VU Online postgraduate block model, delivered in partnership, represents a viable proof of concept that is successful because students experience high levels of support and engagement leading to high retention, satisfaction, and academic success. Even though VU Online represents an unbundling of the university, in our case it does not represent a strategy for breaking up the university to solely tap into new streams of revenue. Rather, VU Online's work at unbundling and entering into public-private partnership creates new value for Victoria University, specifically in regards to a highly supported model of blocked online postgraduate education. This is equally reputation building because VU Online does not exist in isolation and is not separate from Victoria University. Rather, it was always envisaged to be a fundamental component in Victoria University's course offerings to students, in line with the university's strategic intent. University approval for the establishment of VU Online is and has always been underpinned by an expectation and vision to offer a broader suite of courses which, in both content and delivery mechanisms, significantly expand the university's capacity and ability to realise its strategic purpose. As the sector continues to move towards a digitally integrated future, for many prospective Victoria University students, the opportunity to study online in a course with high levels of student support, could be the deciding factor to either pursue a higher education qualification or successfully complete their current higher education course.

Given online education is often under-resourced where academics teach larges classes online without optimum student-staff ratios, a third-party partner like LINC Education becomes critical to success because of its ability to provide responsive academic support students need, precisely when they need it. In our case, unbundling has led to an improvement in the online postgraduate education on offer at Victoria University. We believe we offer a compelling account of what is possible in online education. Inspired by what we have achieved in partnership, VU Online and LINC Education are engaged in research to better understand student beliefs about the support from the online facilitators and the activities embedded within the LMS. Looking forward, and drawing on what we have learned as well as the findings of the research to date, VU online will be well placed to propose a model of rebundling or imaginative reinvention (Lewis \& Shore, 2019) to Victoria University. This will further assist Victoria University in achieving its vison and mission: to be the "University of Opportunity and Success...creating exceptional value for any student from any background and uplifting the communities in which we operate". 


\section{References}

Adair, D., \& Díaz, S. (2014). Stakeholders of quality assurance in online education. In K. Shattuck (Ed.), Assuring quality in online education: Practices and processes at the teaching, resource, and program levels (pp. 3-17). IGI Global.

Agonács, N., \& Matos, J. F. (2019). Heutagogy and self-determined learning: a review of the published literature on the application and implementation of the theory. Open Learning: The Journal of Open, Distance and e-Learning, 34(3), 223-240. https://doi.org/10.1080/02680513.2018.1562329

Aguiar, E., Ambrose, G. A., Chawla, N. V., Goodrich, V., \& Brockman, J. (2014). Engagement vs performance: Using electronic portfolios to predict first semester engineering student persistence. Journal of Learning Analytics, 1(3), 7-33. https://doi.org/10.18608/jla.2014.13.3

Barcan, R. (2016). Academic life and labour in the new university. Routledge. https://doi.org/10.4324/9781315565460

Beer, C., Tickner, R., \& Jones, D. (2014). Three paths for learning analytics and beyond: Moving from rhetoric to reality. Proceedings of the 31st Annual Conference of the Australasian Society for Computers in Learning in Tertiary Education, New Zealand. https://eprints.usq.edu.au/26698/13/Beer_Tickner_Jones_ascilite_2014_PV.pdf

Blaschke, L. M. (2012). Heutagogy and life-ong learning: A review of heutagogical practice and selfdetermined learning. The International Review of Research in Open and Distributed Learning, 13(1), 56-71. https://doi.org/10.19173/irrodl.v13i1.1076

Campbell J. P., DeBlois. P. B., \& Oblinger, D. G. (2007) Academic analytics: A new tool for a new era. EDUCAUSE Review, 42(4), 40-57. https://er.educause.edu/articles/2007/7/academic-analytics-a-newtool-for-a-new-era

Choi, S., Lam, S., Li, K., \& Wong, B. (2018). Learning analytics at low cost: At-risk student prediction with clicker data and systematic proactive interventions. Journal of Educational Technology \& Society, 21(2), 273-290. www.jstor.org/stable/26388407

Clow, D. (2012). The learning analytics cycle: Closing the loop effectively. In S. Dawson, \& C. Haythornthwaite (Eds.), Proceedings of the 2nd International Conference on Learning Analytics and Knowledge (pp. 134-37). https://doi.org/10.1145/2330601.2330636

Coalition for the Academic Workforce (2012). A portrait of part-time faculty members. http://www.academicworkforce.org/CAW portrait 2012.pdf

Craig, R. (2015). College disrupted: The great unbundling of higher education. St. Martin's Press.

Department of Education and Training (2019). Attrition, retention and success rates 2017. https://www.education.gov.au/selected-higher-education-statistics-2018-student-data

Diaz, D., \& Cartnal, R. (2006). Term length as an indicator of attrition in online learning. Innovate: Journal of Online Education, 2(5), 1-5. https://www.learntechlib.org/p/104298/

Dixson, M. D. (2010). Creating effective student engagement in online courses: What do students find engaging? Journal of the Scholarship of Teaching and Learning, 10(2), 1-13. https://eric.ed.gov/?id=EJ890707

Gallager, M. (2014). Micro-economic reform of the Australian higher education industry: Implications of the Abbott Government's Budget of 13 May 2014. Group of Eight Australia. https://go8.edu.au/files/docs/article/edutech presentation - 4 june 2014-pdf version.pdf

Gašević, D., Dawson, S., \& Siemens, G. (2015) Let's not forget: Learning analytics are about learning. TechTrends, 59(1),64-71. https://doi.org/10.1007/s11528-014-0822-x

Greenland, S., \& Moore, C. (2014). Patterns of online student enrolment and attrition in Australian open access online education: A preliminary case study. Open Praxis, 6(1), 45-54. https://doi.org/10.5944/openpraxis.6.1.95

Halloran, L., \& Friday, C. (2018). Can the universities of today lead learning for tomorrow?: The university of the future. https://medicine.uq.edu.au/files/42076/and $\% 20$ it $\% 20$ doesn $\%$ E2\%80\%99t $\% 20$ even $\% 20$ exist $\% 20$ yet.

Harwood, K. J., McDonald, P. L., Butler, J. T., Drago, D., \& Schlumpf, K. S. (2018). Comparing student outcomes in traditional vs intensive, online graduate programs in health professional education. $B M C$ Medical Education, 18(1),1-9. https://doi.org/10.1186/s12909-018-1343-7

Haydarov, R., Moxley, V., \& Anderson, D. (2013). Counting chickens before they are hatched: An examination of student retention, graduation, attrition, and dropout measurement validity in an online master's environment. Journal of College Student Retention: Research, Theory \& Practice, 14(4), 429-449. https://doi.org/10.2190/CS.14.4.a 
Jaggars, S. S., \& Xu, D. (2016). How do online course design features influence student performance? Computers \& Education, 95, 270-284. https://doi.org/10.1016/j.compedu.2016.01.014

Jordan, K. (2015). Massive open online course completion rates revisited: Assessment, length and attrition. The International Review of Research in Open and Distributed Learning, 16(3), 341-358. https://doi.org/10.19173/irrodl.v16i3.2112

Komljenovic, J., \& Robertson, S. L. (2016). The dynamics of 'market-making' in higher education. Journal of Education Policy, 31(5), 622-636. https://doi.org/10.1080/02680939.2016.1157732

Lewis, N., \& Shore, C. (2019). From unbundling to market making: Reimagining, reassembling and reinventing the public university. Globalisation, Societies and Education, 17(1), 11-27. https://doi.org/10.1080/14767724.2018.1524287

Li, K. C., \& Wong, B. T.-M. (2019). Factors related to student persistence in open universities: Changes over the years. The International Review of Research in Open and Distributed Learning, 20(4). https://doi.org/10.19173/irrodl.v20i4.4103

Liu, D. Y. T., Bartimote-Aufflick, K., Pardo, A., \& Bridgeman, A. J. (2017). Data-driven personalization of student learning support in higher education. In A. Peña-Ayala (Ed.), Learning analytics: Fundaments, applications and trends. A view of the current state of the art to enhance e-learning (pp. 180-189). Springer.

Liu, D. Y. T., Atif, A., Froissard, J. C., \& Richards, D. (2019). An enhanced learning analytics plugin for Moodle: Student engagement and personalised intervention. Proceedings of ASCILITE - Australasian Society for Computers in Learning and Tertiary Education, Perth, 180-189.

Moore, C., \& Greenland, S. (2017). Employment-driven online student attrition and the assessment policy divide: An Australian open-access higher education perspective. Journal of Open, Flexible and Distance Learning, 21(1), 52-62.

Norton, A. (2013). The unbundling and re-bundling of higher education. The Grattan Institute. https://grattan.edu.au/wp-content/uploads/2014/05/905_norton_alliance_21.pdf

Norton, A., \& Cherastidtham, I. (2018). Mapping Australian higher education 2018. The Grattan Institute. https://grattan.edu.au/wp-content/uploads/2018/09/907-Mapping-Australian-highereducation-2018.pdf

Oregon, E., McCoy, L., \& Carmon-Johnson, L. (2018). Case analysis: Exploring the application of using rich media technologies and social presence to decrease attrition in an online graduate program. Journal of Educators Online, 15(2).

Pardo, A. (2014). Designing learning analytics experiences. In J. A. Larusson \& B. White (Eds.), Learning Analytics (pp. 15-38). Springer. https://doi.org/10.1007/978-1-4614-3305-7_2

Patterson, B., \& McFadden, C. (2009). Attrition in online and campus degree programs. Online Journal of Distance Learning Administration, 12(2). https://www.westga.edu/ distance/ojdla/summer122/patterson112.html

Philips, J. (2017). Don't look now, but the great unbundling has spun into reverse. New York Times. https://www.nytimes.com/2017/02/14/business/dealbook/bundling-online-services.html

Pittenger, A., \& Doering, A. (2010). Influence of motivational design on completion rates in online selfstudy pharmacy-content courses. Distance Education, 31(3), 275-293. https://doi.org/10.1080/01587919.2010.513953

Revere, L., \& Kovach, J. V. (2011). Online technologies for engaged learning a meaningful synthesis for educators. Quarterly Review of Distance Education, 12(2), 113-124. https://pdfs.semanticscholar.org/5057/da57b469a5133f7b5f375a9c2e7cb4ba3ea8.pdf

Rosanes, M. (2020). 'Revolutionary' teaching model delivers amid online transition. https://www.theeducatoronline.com/he/news/revolutionary-teaching-model-delivers-amid-onlinetransition $/ 271570$

Sancho-Vinuesa, T., Escudero-Viladoms, N., \& Masià, R. (2013). Continuous activity with immediate feedback: A good strategy to guarantee student engagement with the course. Open Learning: The Journal of Open, Distance and e-Learning, 28(1), 51-66. https://doi.org/10.1080/02680513.2013.776479

Simonson, M. R., Smaldino, S. E., \& Zvacek, S. (2015). Teaching and learning at a distance: Foundations of distance education (6th ed.). Information Age Publishing.

Simpson, O. (2012). Supporting students for success in online and distance education. Routledge, https://doi.org/10.4324/9780203095737

Sivarajah, R. T., Curci, N. E., Johnson, E. M., Lam, D. L., Lee, J. T., \& Richardson, M. L. (2019). A Review of innovative teaching methods. Academic Radiology, 26(1), 101-113.

https://doi.org/10.1016/j.acra.2018.03.025 
Stone, C. (2019). Online learning in Australian higher education: Opportunities, challenges and transformations. Student Success, 10(2), 1-11. http://doi.org/10.5204/ssj.v10i2.1299

Swinnerton, B., Ivancheva, M., Coop, T., Perotta, C., Morris, N., Swartz, R., Czerniewicz, L., Cliff, A., \& Walji, S. (2018). The unbundled university: Researching emerging models in an unequal landscape. Preliminary findings from fieldwork in South Africa. In M Bajic, N. B Dohn, M. de Laat, P. Jandric, \& T. Rybery (Eds.), Proceedings of the 11th International Conference on Networked Learning (pp. 218-226). http://eprints.whiterose.ac.uk/131028/

Tait, A. W. (2018). Education for development: from distance to open education. Journal of Learning for Development - JL4D, 5(2), 101-115. https://j14d.org/index.php/ej14d/article/view/294

Thompson, M. M., \& Kuhne, G. W. (2014). Ethics matter: Assuring quality at the academic program level. In K. Shattuck (Ed.), Assuring quality in online education: practices and processes at the teaching, resource, and program levels. (pp. 124-135). Stylus.

Tucker, J. P., \& Neely, P. W. (2010). Unbundling faculty roles in online distance education programs. International Review of Research in Open and Distributed Learning, 11(2), 20-32.

Verbert, K., Duval, E., Klerkx, J., Govaerts, S., \& Santos, J. L. (2013). Learning analytics dashboard applications. American Behavioral Scientist, 57(10), 1500-1509. https://doi.org/10.1177/0002764213479363

Viberg, O., \& Grönlund, Å. (2017). Understanding students' learning practices: Challenges for design and integration of mobile technology into distance education. Learning, Media and Technology, 42(3), 357-377. https://doi.org/10.1080/17439884.2016.1088869

Corresponding author: Chris Walsh, chris.walsh@,vu.edu.au

Copyright: Articles published in the Australasian Journal of Educational Technology (AJET) are available under Creative Commons Attribution Non-Commercial No Derivatives Licence (CC BY-NCND 4.0). Authors retain copyright in their work and grant AJET right of first publication under CC BYNC-ND 4.0.

Please cite as: Walsh, C., Mital, A., Ratcliff, M., Yap, A., \& Jamaleddine, Z. (2021). A public-private partnership to transform online education through high levels of academic student support. Australasian Journal of Educational Technology, 36(5), 30-45. https://doi.org/10.14742/ajet.6107 